\title{
Study on the Reasonable Length of Core Soil in Shallow Buried Large Section Tunnel
}

\author{
Xingliang Jin ${ }^{1, a}$, Bin Liang ${ }^{1, b}$
}

Civil Engineering School, Henan University of Science and Technology, Luoyang 471023, China

a1278461291@qq.com, lliangbin4231@163.com

Keywords: shallow flat tunnel; super section; double side slope method; excavation rational length Abstract. Taking Chongqing Metro Line 5 tunnel project as an engineering example, which is a shallow buried large section tunnel. Study on the length of core soil in the tunnel excavation. The numerical simulation software MIDAS-GTS was used to establish the three dimensional solid model which under different length of core soil. The results were compared with the measured data, and the correctness and effectiveness of the proposed method were verified. The mechanical properties and deformation index of surrounding rock under three different length of core soil were integrated analysis. Finally, the reasonable length of middle wall core soil was determined to be 25 m. The methods and conclusions of this paper can be used as reference for the study of the reasonable length of the middle wall core soil in the flat super large section tunnel. It provided a theoretical support for the construction.

\section{Introduction}

The method of double side slope method used in large flat section tunnel in general [1]. The large section divided into small section relatively closed excavation which can reduce the disturbance to the surrounding rock in excavation process. The middle wall core soil can play a supporting role for the tunnel in construction stage. The middle wall core soil plays a key role to keep the stability of working face [2-3].

The study on the length of middle wall core soil excavation was mainly through the analysis of surrounding rock deformation and surrounding rock stress [4]. The field construction can't be carried out a variety of tests, so mainly through numerical simulation software simulation. Finally, the numerical analysis and field monitoring data were compared and analyzed. The finite element numerical was used to analyze the law of surrounding rock deformation. The effect of three kinds of length of middle wall core soil on the stability of surrounding rock in tunnel face was analyzed. The numerical results were compared with the measured data. Select a reasonable length of core soil, which provide a reference for the application of the method in super section flat shallow tunnel.

\section{Project Profile}

The tunnel of line No. 5 of Chongqing Metro is a single arch tunnel with four lines. The maximum height of the tunnel excavation space nearly $17.2 \mathrm{~m}$, span is $27.6 \mathrm{~m}$ and the total excavation area is $388.47 \mathrm{~m} 2$, flat rate close to 0.62 . The main site of groundwater is perched and weathering of bedrock fissure water. The field outcrop stratum consists of sandy mudstone, the quality grade is IV. It was constructed by the method of symmetrical excavation step sequence of double side slope method according to the design of large cross section tunnel interval. 


\section{Finite Element Model}

Model parameters. The tunnel surrounding rock constitutive model is Mohr-coulomb model. The linear elastic model used in bolt, steel and concrete. Three-dimensional solid element was used in surrounding rock. Specific parameters are shown in Tab.1 below.

Tab.1 Basic mechanical parameters of tunnel surrounding rock and structural material

\begin{tabular}{|c|c|c|c|c|c|c|}
\hline Type & $E / M P a$ & $\gamma / \mathrm{kN} / \mathrm{m}^{3}$ & $C / \mathrm{MPa}$ & $\varphi^{{ }^{o}}$ & $\mu$ & Constitutive model \\
\hline Sandy mudstone & 1660 & 25.6 & 0.75 & 33.3 & 0.36 & Mohr-coulomb \\
\hline Sprayed concrete & 28000 & 23 & $/$ & $/$ & 0.2 & Linear elasticity \\
\hline Bolt & 200000 & 78 & $/$ & $/$ & 0.3 & Linear elasticity \\
\hline Lining & 33500 & 25 & $/$ & $/$ & 0.2 & Linear elasticity \\
\hline
\end{tabular}

Boundary condition. The horizontal direction of the left and right boundaries of the model was constrained. The top was a free boundary. The vertical and horizontal directions of the bottom boundaries were constrained.

Finite element model. The tunnel excavation process was simulated by the assistant of construction stage of MIDAS-GTS. According to the finite boundary and finite element analysis theory and combined with practical engineering, the calculation model of surrounding rock on both sides with 2 times of the diameter of the tunnel surrounding rock bottom width, 2 times of the diameter of the tunnel as finite element analysis, the tunnel depth is $50 \mathrm{~m}$. Fig.1 shows the finite element model. Fig. 2 shows that the deformation of surrounding rock during excavation.
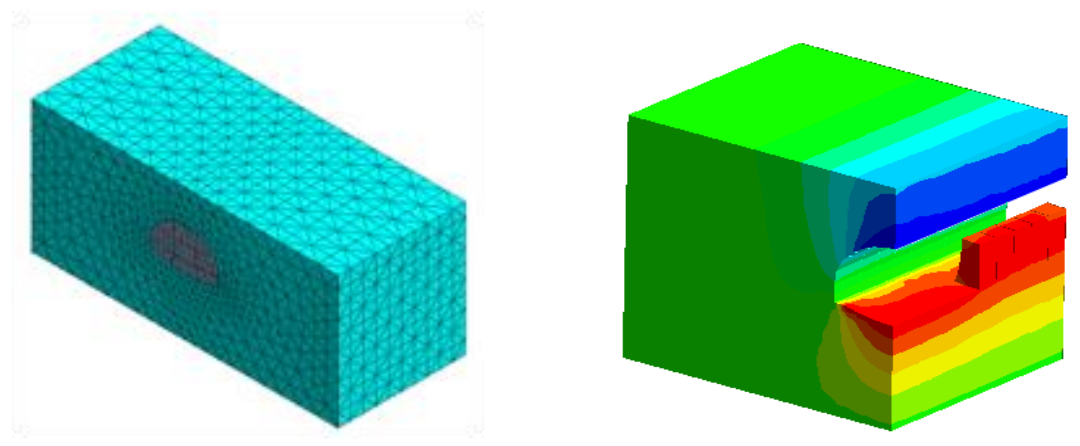

Fig.1 Finite element model

Fig.2 Vertical displacement of surrounding rock

\section{Calculation Results and monitoring Analysis}

The deformation analysis of surrounding rock. It can be seen from Fig.3 that the displacement filed of the surrounding rock in the excavation process was symmetrical. The arch was sinking and the inverted arch rises under the action of ground stress. From Fig.3 (a), it can be seen that the vault settlement of the demolition section of the situation of $25 \mathrm{~m}$ increased when the middle wall core soil was removal. The settlement value from the excavation face to working face was gradually decreased. In the case of removal of middle wall core soil should be supported timely to prevent large settlement of arch crown. The displacement field of the surrounding rock was symmetrically distributed after excavation. The settlement value of the arch was $8.18 \mathrm{~mm}$, and the uplift of the surrounding rock was about $6.20 \mathrm{~mm}$. 


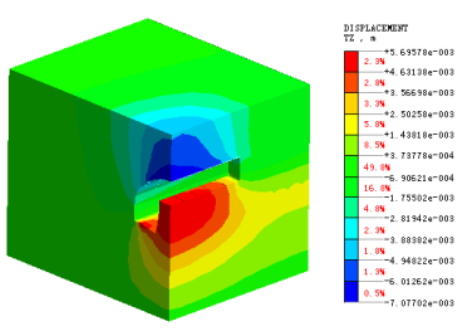

(a) core soil removal

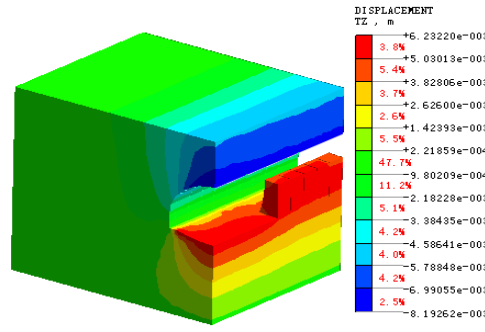

(b) heading excavation
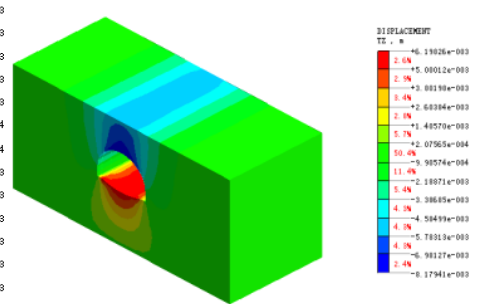

(c) complete excavation

Fig.3 Vertical displacement of surrounding rock in excavation (Unit: $\mathrm{m}$ )

It can be seen from Fig.4 6 that the index gradually increased before heading through the bilateral. The value of each index increased significantly when the middle wall core soil was removal in the partition of 7 9. The tunnel structure lost support with the cause of middle wall core soil was removed and can't be closed.

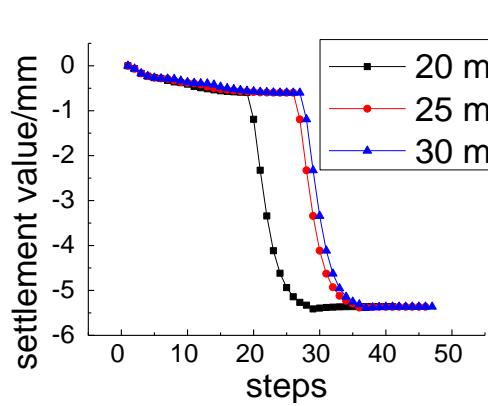

Fig.4 Surface subsidence

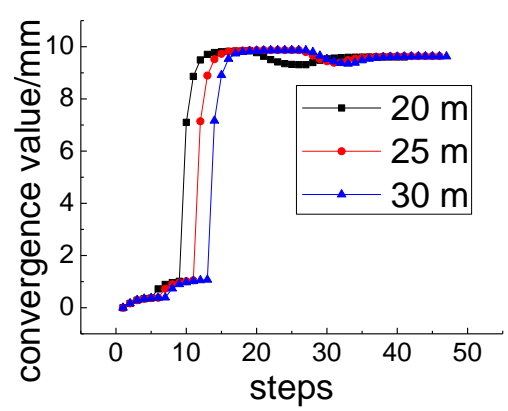

Fig.5 Horizontal convergence of arch foot

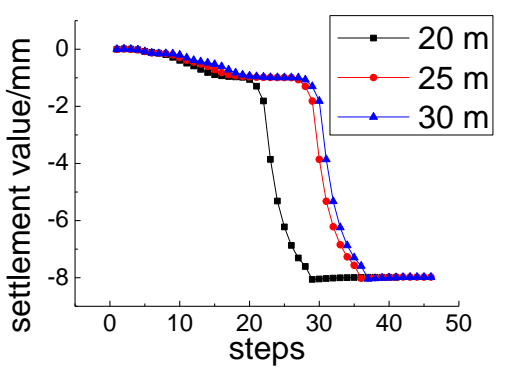

Fig.6 Vault settlement

Deformation analysis of working face extrusion. It can be seen from Fig.7 that the maximum value of three working face extrusion displacement were in different height positions. The operating condition one and two were in the vicinity of the height of $4 \mathrm{~m}$. The working condition of three was in the vicinity of the height of $6 \mathrm{~m}$. The maximum value of working condition one and two is in the middle of the height of core soil, which indicates that the thickness of the middle wall core soil is reasonable. The status of the three appears in the middle region on the face, which indicates that the self stability was poor. The thickness of the remaining core soil is small, which is equivalent to the slender rod. The maximum value of longitudinal displacement was $0.21 \mathrm{~mm}$ in no. 1 condition, 0.28 $\mathrm{mm}$ in no. 2 condition, $0.23 \mathrm{~mm}$ in no. 3 condition. Three working face extrusion displacement were not big. The stability of surrounding rock of working face is good. However, the thickness of remaining of middle wall core soil is thin in condition no.3. The construction efficiency was improved in the case of the core soil length is $25 \mathrm{~m}$. On the whole, the length is $25 \mathrm{~m}$ which is more reasonable.

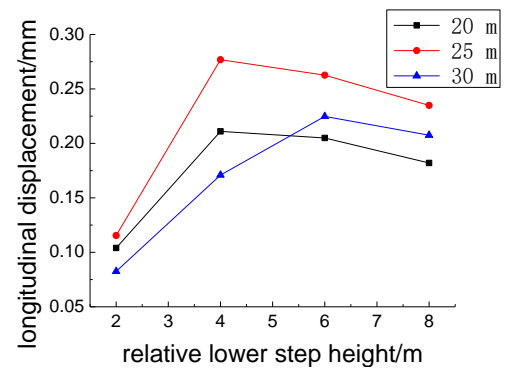

Fig.7 Extrusion displacement of tunnel working face

Comparative analysis of numerical calculation and monitoring data. It can be seen from Tab.2 that the horizontal convergence calculated values agree well with the measured values. The 
ground settlement data was bigger than the numerical simulation data. On the whole, the measured values were in good agreement with the calculated values, the numerical results are reasonable, and the reasonable optimization is $25 \mathrm{~m}$.

Tab.2 Comparison of calculated and measured data

\begin{tabular}{|c|c|c|c|c|c|c|}
\hline \multirow{2}{*}{ condition } & \multicolumn{2}{|c|}{$\begin{array}{c}\text { Ground settlement } \\
\text { value/mm }\end{array}$} & \multicolumn{2}{c|}{ Crown settlement/mm } & \multicolumn{2}{c|}{$\begin{array}{c}\text { Horizontal convergence of } \\
\text { arch feet/mm }\end{array}$} \\
\cline { 2 - 7 } & calculated & Measure & calculated & Measure & calculated & Measure \\
\hline $25 \mathrm{~m}$ & 5.38 & 12.30 & 8.18 & 10.60 & 9.64 & 13.45 \\
\hline
\end{tabular}

\section{Conclusions}

The excavation of a cycle, the maximum settlement value of vault was in the excavation initial entrance. The value gradually decreased from the entrance to the tunnel face. The values of the uplift show the same law at the bottom of the tunnel. Therefore, the excavation should be carried out in a timely manner to support and closed ring, to ensure the stability of the tunnel surrounding rock during construction.

The working face extrusion displacement value appeared in the height of the middle of core soil in the condition of one and two. The working condition three was in the position of height $2 / 3$, the length of the remaining core soil was small, less than the $1 / 2$ length of the tunnel, the middle wall core soil was easy to lose the stability of surrounding rock. By comparison, the length of middle wall core soil should not be more than $1 / 2$ length of the tunnel in this project.

Finally, the length of the core soil was determined the best in the project which is a flat super large section tunnel. The construction efficiency was improved and the cost was saved which under the premise of ensuring safety and quality. The effect of this ideal was achieved in the following construction.

\section{References}

[1] P.M. Huang, H. Kong, M. S. Wang, H. B. Yao, Effect of keeping core soil on stability of tunnel working face, J. Chinese jounal of rock mechanics and engineering. 3 (2005)521-525. (in Chinese)

[2] X. Li, C. He, P. Geng, et al, Construction schemes and supports mechanical characteristics of shallow embedded lage-section tunnel, J . Journal of central south university ( Sience and Technology ). 9 (2015)3386-43395. (in Chinese)

[3] J.X. Yuan, Study on reasonable bench length during construction of tunnel in weak broken surrounding rock, J. Highway Engineering, 4 (2013) 66-69. (in Chinese)

[4] Z.S. Shao, X.Z. Li, F.C. Chen, Y.Q. Liang, Stability analysis on the surrounding rocj of large span highway tunnel in soft rock, J. Chinese journal of underground space engineering. 6 (2012) 1221-1243. (in Chinese) 